\title{
Investigation of Microorganisms Associated with the Foam of a Submerged Membrane Bioreactor in Japan
}

\author{
BEGUM SHAILA LUXMY ${ }^{1 *}$ and KAZUO YAMAMOTO ${ }^{2}$ \\ ${ }^{1}$ Department of Urban Engineering, University of Tokyo, 7-3-1, Hongo, Bunkyo-Ku, Tokyo 113-8656, Japan \\ ${ }^{2}$ Environmental Science Center, University of Tokyo, 7-3-1, Hongo, Bunkyo-Ku, Tokyo 113-0033, Japan
}

(Received August 18, 2002-Accepted February 17, 2003)

\begin{abstract}
Microorganisms associated with the foam and their status before and after foaming in a submerged membrane bioreactor situated in Japan, are described. The microorganisms associated with membrane bioreactors have not yet been fully explored, as this is a relatively recent technology. An important finding was that one of the most discussed filaments Microthrix parvicella, the occurrence of which has rarely been reported in Japan, dominated in the foam of this bioreactor. Various types of filaments were identified in the foam based on morphology and available specifies-specific oligonucleotide probes but they were mainly Nocardia spp., Microthrix parvicella, Nostocoida limicola, type 1851, type 0041, type 1701, type 0675, type 021n, type 0914 etc. Also Microthrix pervicella, species from Mycolata groups and total eubacteria in the before and after foaming-samples were quantified using the oligonucleotide probes MPA 223, MYB and EUB, respectively. The ratio of MPA to EUB (approx. 22\%) in the foam was found to be much higher than the ratio of MYB to EUB (approx. 6\%). The investigation suggested that Microthrix parvicella was mainly responsible for the onset of foaming in this plant. This study provides information about the occurrence, composition and ratio of foaming filaments that might occur in a membrane bioreactor (MBR) along with the most important and discussed filament Microthrix parvicella.
\end{abstract}

Key words: FISH, filaments, foam, membrane bioreactor, Microthrix parvicella

One wide spread problem in activated sludge is the formation of a viscous thick stable foam. Numerous undesirable and unaesthetic problems are associated with the foaming. Such foam appears as a bacterial biomass floating on the surface of the aeration basin. These viscous foams have been associated with the presence of filamentous mycolic acid-containing actinomycetes (mycolata). A number of different actinomycetes have also been isolated and identified from foaming plants including Nocardia, Rhodococcus, Gordona, Tsukamurella and Mycobacterium, as well as other Gram-positive bacteria such as Microthrix parvicella ${ }^{12)}$.

Attempts have been made to isolate and identify the foam-formers. Their analysis and identification are impor-

\footnotetext{
* Corresponding author; Begum Shaila Luxmy, PhD, Wastewater Technology Centre, Environment Canada, 867 Lakeshore Road, Burlington ONL7R 4A6, Canada, E-mail: luxmy.begum@ec.gc.ca, Tel: +1-905-319-6957, Fax : +1-905-336-4858
}

tant for selecting an appropriate and reliable control measure. Analyzing and identifying the causative population may lead to the solution of the foaming problem. Also some are pathogens. Although G. amarae, Skermania piniformis and M. parvicella are not pathogens, Nocardia asteroides, Nocardia farcinica and Rhodococcus equi are potential pathogens ${ }^{22)}$.

In membrane bioreactors (MBRs), solid-liquid separation is fulfilled by membrane separation. This system replaces the gravitational sedimentation of conventional activated sludge and provides complete solid-liquid separation by the use of a membrane. The MBR process is different from the Conventional Activated Sludge (CAS) process due to the long sludge retention time and low F/M ratio. As a result, the microbial community of this system may be quite different from that of a conventional activated sludge system. But presently, little information is available about the microbial 
community for this process and almost nothing is known about the potential foam-causing organisms. So, the foamcausing population in MBR demands more explicit analysis.

In this study, the organisms associated with the foam of a submerged membrane bioreactor and their status before and after foaming were investigated. In this plant, problems started with an increase in transmembrane pressure. At that time, turbidity in the supernatant of the sludge was noticeable. These problems began in the winter (in the month of March). The previous winter the plant had faced a similar type of situation. So, an analysis of the microbial community of this plant was conducted to elucidate the cause of the problem. One month later, the transmembrane pressure was reduced but a severe foaming occurred in the plant. Both aeration and non-aeration tanks were covered with a thick dense foam. The scope of this study was to provide information about the composition and ratio of foaming filaments that might occur in MBRs.

\section{Materials and Methods}

\section{Description of the plant}

The foaming in a pilot-scale submerged MBR, which was situated in Japan, was investigated. This pilot plant was receiving $50 \mathrm{~m}^{3}$ of domestic wastewater per day. The type of membrane used in the plant was a hollow fiber membrane with a $0.4 \mu \mathrm{m}$ pore size. The HRT of both aeration and nonaeration tanks was 3.2 hours.

\section{Staining of the sample}

Gram staining and Neisser stainning were performed according to methods described by Jenkins et al. ${ }^{12)}$.

\section{Fluorescent in situ hybridization (FISH) technique}

Suspended foam samples were fixed using $4 \%$ paraformaldehyde for 1 minute as optimized by De Los Reyes et $a l .{ }^{4}$. Samples were immobilized on gelatin-coated slide glass by air-drying. To increase the permeability of the probes, the cell spots were covered with lysozyme (from chicken egg white, SIGMA), in a volume of about 10 microliters (10 $\mathrm{mg} / \mathrm{ml}$ of $100 \mathrm{mM}$ Tris, $50 \mathrm{mM}$ EDTA) and were incubated for 10 minutes at $4{ }^{\circ} \mathrm{C}^{6,23)}$. Ethanol treatments $(50 \%, 80 \%$, $98 \%$ for $3 \mathrm{~min}$ each) were carried out before and after the enzyme treatment ${ }^{1,6)}$. In situ hybridizations were performed by using the methods described earlier by Amann ${ }^{1)}$ except for the MYB probe for which hybridization was performed as suggested by De Los Reyes et al. ${ }^{4}$. DAPI staining was carried out after the FISH procedure. The formamide percentages used for different probes are shown in Table 1. The hybridization mixture was removed with washing buffer, which was then removed with Milli-Q water. The hybridization slides were air-dried and mounted with slow fade light (Molecular probes, Leiden, the Netherlands) as an anti fade reagent. A TCS-NT confocal laser scanning microscope (CLSM) system (TCS-NT, Lieca Microsystems, Heidelberg, Germany) with an $\mathrm{Ar} / \mathrm{Kr}$ laser was used for the observation and image acquisition. The objective lens was PL APO x63 (oil immersed).

\section{Description of the probes used}

The probes used in order to analyze the bacterial community are described in Table 1. XRITC-, Cy5- and FITClabeled probes were used in this study.

\section{Quantification of specific probes with respect to eubacteria}

For quantification purposes the samples were sonicated first and later whole cell hybridization was conducted. Samples were always doubly hybridized using the EUB338 probe along with the specific probe to be quantified. Eight different pictures were taken for each probe (for both EUB 338 and a specific probe, in the same field) from eight randomly selected different positions of a slide glass. Later the area covered by the specific probe and also the area covered

Table 1. Probes used in this study.

\begin{tabular}{|c|c|c|c|c|}
\hline Probe & Probe Sequence (5'-3') & Target position ${ }^{\mathrm{a}}$ & Formamide (\%) & Ref. \\
\hline EUB 338 & GCTGCCTCCCGTAGGAGT & $16 \mathrm{~S}, 338-355$ & 20 & Amann et al. (1990) \\
\hline MYB & CAGCGTCAGTTACTACCCAGAG & $16 \mathrm{~S}, 0736-0757$ & 30 & De los Reyes et al. (1997) \\
\hline G.am & CACCCACCCCCATGCAGG & $16 \mathrm{~S}, 0192-0209$ & 30 & De los Reyes et al. (1997) \\
\hline SNA & CATCCСCСТCTACCGTAC & $16 S, 656-673$ & 45 & Wagner et al. (1994) \\
\hline TNI & СТССТСТСССАСАТТСТА & $16 \mathrm{~S}, 652-669$ & 45 & Wagner et al. (1994) \\
\hline MPA 223 & GCCGCGAGACCCTCCTAG & $16 \mathrm{~S}, 223-240$ & 20 & Erhart et al. (1997) \\
\hline $21 \mathrm{~N}$ & ТСССТСТСССАААТТСТА & $16 \mathrm{~S}, 652-669$ & 35 & Wagner et al. (1994) \\
\hline
\end{tabular}

a (E. coli numbering) 
by EUB 338 in the same field of the slide glass, taken as images, were calculated using Quantimet Q600HR software (Leica). Total fluorescent area was calculated based on a threshold in which signals from the probe fluorescence and from mechanical noise were clearly separated. Then the area ratios of each specific probe with the eubacterial probe were calculated from those eight sets of images and subsequently the mean and standard deviation were calculated.

\section{Results and Discussion}

\section{Before foaming occurred}

The problem initiated in the plant with an increase in the transmembrane pressure as mentioned in the introduction. At that time, turbidity was high in the sludge-supernatant. Then the sludge samples were analyzed as to biological properties. Gram staining showed that, lots of Gram-positive rod and coccoid shaped dispersed cells were present in the supernatant of the sludge. Though morphologically the cells looked quite similar, Gram-staining alone was not enough to reveal whether they consisted of several species or not. The probe EUB 338 was applied to the supernatant and the sample was also stained with DAPI simultaneously. It was found that almost all of the biomass stained with DAPI gave a bright signal with EUB 338 (Fig. 1A). From the FISH analysis, it was confirmed that the supernatant of the sludge consisted of dispersed single cell bacteria, mostly irregular rods and cocci. So these dispersed bacterial cells might be responsible for increasing the transmembrane pressure in the reactor. However, it was not clear whether these bacterial cells were directly related with the foaming onset that occurred in the plant after one month. By observing the Gram-
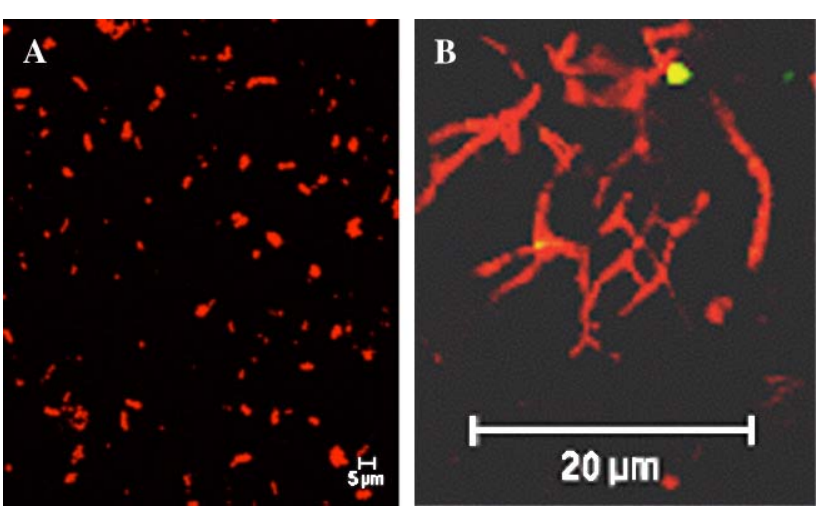

Fig. 1. A) Bacterial cells identified in the supernatant of the sludge by the probe Eub 338 (XRITC-labeled; B) Probe G.am labeled with XRITC showed Gordona amarae in the sludge sample before foaming occurred.
Table 2. Condition of sludge in the reactor.

\begin{tabular}{|c|c|}
\hline Parameter & Values \\
\hline \multicolumn{2}{|l|}{ Before foaming occurred (in March):- } \\
\hline $\begin{array}{l}\text { Aeration tank sludge diluted four-fold with } \\
\text { treated water } \mathrm{SV}_{30}(\mathrm{X} 4)\end{array}$ & $45 \%$ \\
\hline \multicolumn{2}{|l|}{ Aeration tank sludge condition } \\
\hline Water temperature & $16.1^{\circ} \mathrm{C}$ \\
\hline MLSS & $11,000 \mathrm{mg} / \mathrm{l}$ \\
\hline DO & $2.3 \mathrm{mg} / 1$ \\
\hline $\mathrm{pH}$ & 6.7 \\
\hline \multicolumn{2}{|l|}{ After foaming occurred (in April):- } \\
\hline $\begin{array}{l}\text { Aeration tank sludge diluted four-fold with } \\
\text { treated water } \mathrm{SV}_{30}(\mathrm{X} 4)\end{array}$ & $28 \%$ \\
\hline \multicolumn{2}{|l|}{ Aeration tank sludge conditions } \\
\hline Water temperature & $19^{\circ} \mathrm{C}$ \\
\hline MLSS & $7000 \mathrm{mg} / \mathrm{l}$ \\
\hline DO & $2.7 \mathrm{mg} / \mathrm{l}$ \\
\hline $\mathrm{pH}$ & 6.6 \\
\hline
\end{tabular}

stained images of the sludge, it was found that, the sample contained numerous filaments along with Gram-positive Nocardia like branching organisms. In the sludge, the presence of Gordona amarae was confirmed with the speciesspecific probe G. am (Fig. 1B). Also the presence of other foam-causing organisms was observed after dual hybridization of the sample with both the group-specific probe for mycobacterium complex (MYB) and the species-specific probe for Gordona amarae. According to Jenkins et al. ${ }^{12)}$, Nocardia growth can be promoted by the presence of surfactants. Again, slowly biodegradable surfactants can cause floc dispersion. This type of floc dispersion problem can vary seasonally, being worse in the colder season, because the biodegradation rate of some of the causative surfactants is significantly decreased at low temperatures. As the trouble started in winter (first noticed in March), this might be one explanation. However, both Gram staining of the samples and FISH analysis showed that the sludge contained a significant number of foam-causing organisms in each floc, which indicated that the reactor was very much prone to foaming. The sludge property and reactor conditions are given in Table 2 (before foaming).

\section{After foaming occurred}

After foaming occurred, foam samples from both aeration and non-aeration tanks were observed carefully. The properties of the sludge and reactor conditions are given in Table 2 (after foaming). The Gram staining of the foam samples revealed that other than Nocardia-like branching organisms, 
it contained a significant number of non-branching, Grampositive cells observed in tangles or coiled in the flocs or sometimes as bent or curved filaments in the bulk solution. To confirm the identification, Neisser-staining was done. They appeared Neisser positive and close observation showed that the granules were actually appeared positive rather than the entire trichome. From the above description, it is very clear that this organism has very high morphological similarity with the classical foam causing organisms Microthrix parvicella. But also the organisms discussed above have high similarity with Nostocoida limicola I. Notocoida limicola resembles Microthrix parvicella except in its Neisser stain properties-for Nostocoida limicola the entire trichome is positive though sometimes negative while for Microthrix parvicella, the granules are positive ${ }^{12)}$. Gram staining alone was not enough to identify this visually dominant organism. So the next step in the analysis was conducted with different types of oligonucleotide probes.

Molecular taxonomists have found significant rRNA homology between actinomycetes and a group of related bacteria, all characterized by Gram-positive staining and a high $\mathrm{G}+\mathrm{C}$ content of DNA, and consequently proposed a group named the 'actinomycetes branch' or 'Gram-positive bacteria with high $\mathrm{G}+\mathrm{C}$ content of $\mathrm{DNA}^{\prime}{ }^{16)}$. A significant presence of this high $\mathrm{G}+\mathrm{C}$ content group was observed in the sludge of this plant's samples when the samples were dually hybridized with the probes HGC69a and EUB. Theoretically, the HGC69a probe could be expected to bind to Microthrix parvicella filaments because this organism is a member of the actinomycete subphylum. But it had been found that the 23S rRNA of Microthrix parvicella has three mismatches to probe HGC69a in the target region, effectively preventing probe bindings ${ }^{6}$. In this case when the foam sample was dually hybridized with the EUB and HGC69a probes, the suspected coiled shaped filaments gave a bright signal with EUB but no signal was received from HGC 69a (Fig. 2). So this experiment also increased the possibility that the organism might be Microthrix parvicella, presently the most discussed but least understood foamcausing organism.

Erhart et al. $\left.{ }^{6}\right)$ developed probes for in situ identification of Microthrix parvicella in activated sludge. According to the authors, these probes were highly specific for the filaments morphologically identified as Microthrix parvicella as none of a wide range of pure cultures of bacteria gave positive hybridization signals with any of the MPA probes. In order to identify the target organisms accurately, the probe MPA 223 developed by Erhart et al. ${ }^{6}$ was applied in the foaming samples of the pilot plants. Clear and bright

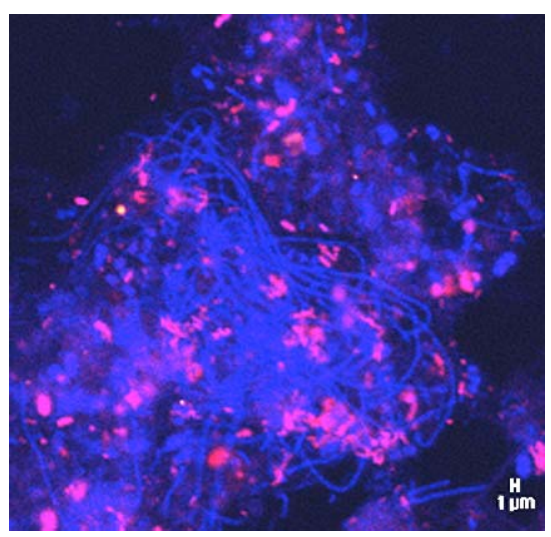

Fig. 2. The unbranched coiled filaments like "Microthrix parvicella" did not bind with probe HGC69a (XRITC-labeled) while a bright signal was obtained from EUB (Cy 5-labeled.).

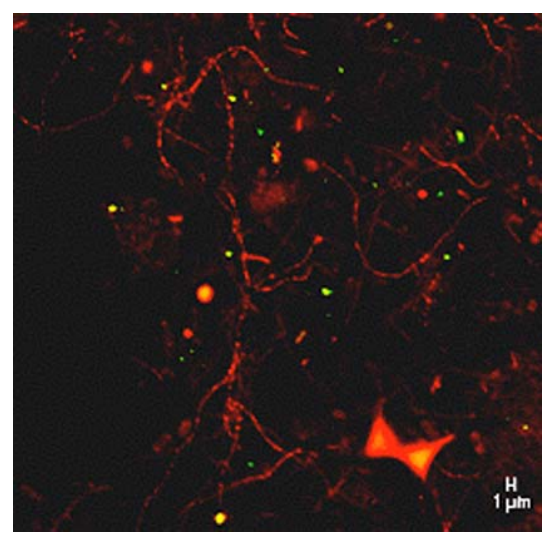

Fig. 3. Foam samples hybridized with probe MPA 223 (XRITClabeled) showed Microthrix parvicella.

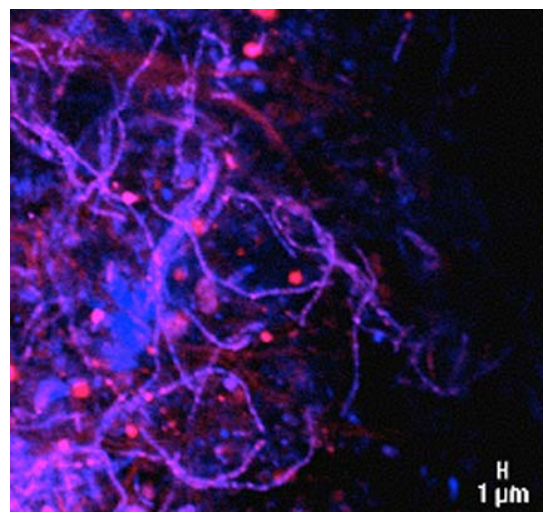

Fig. 4. Foam samples dually hybridized with probe MPA 223 (XRITC-labeled) and EUB 338 (Cy 5-labeled).

signals were received from the susceptible filaments (Fig. 3 and 4). Although many biological scumming or foaming 

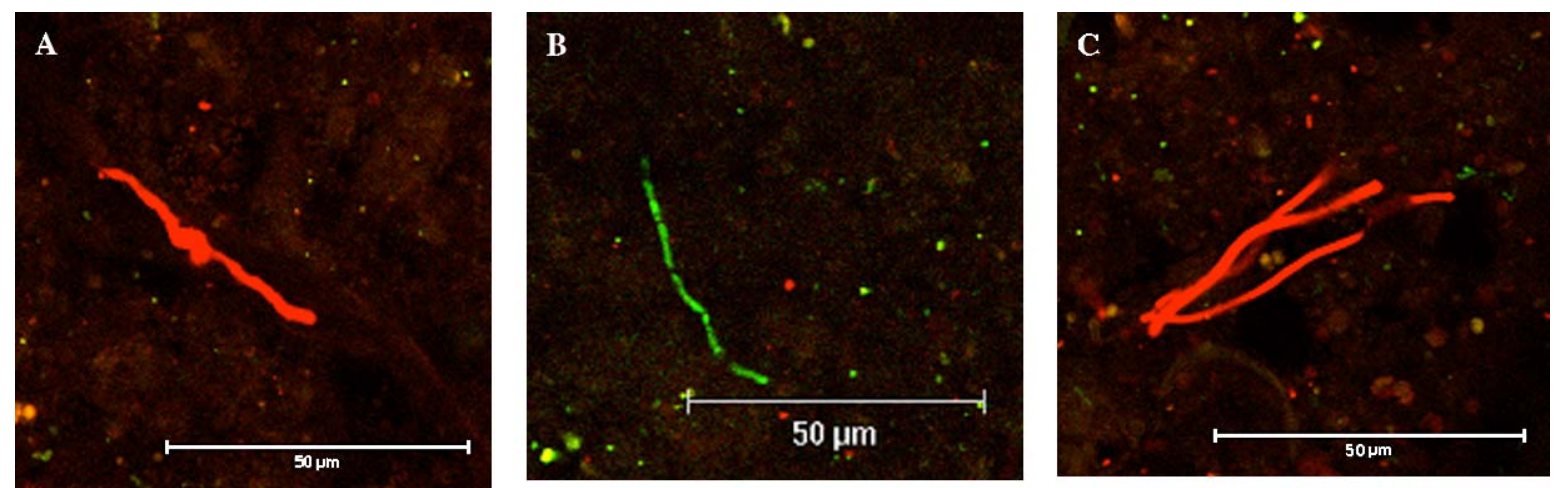

Fig. 5. A) Whole cell hybridization of type $021 \mathrm{~N}$ in the foam sample with the oligonucleotide probe $21 \mathrm{~N}$ (XRITC-labeled.); B) Sphaerotilus natans was detected with the probe SNA labeled with FITC; C) Probe TNI labeled with XRITC identified the species Thiothrix nivea in the foam sample.

problems in activated sludge plants have been reported in $\mathrm{Japan}^{10,14)}$, the majority of these were found to be due to the presence of actinomycetes. There have been few cases reported of foaming related to "Microthrix parvicella" in Japan till now ${ }^{11)}$.

Whole cell identification of the other filamentous microorganisms present in the foam was done with the help of available oligonucleotide probes. The type $021 \mathrm{~N}$ was detected with the probe $21 \mathrm{~N}$ and images are given in Fig. 5A. The probe TNI specific to Thiothrix nivea also detected a number of filaments (Fig. 5B). Sphaerotilus natans was detected in the sample with the probe SNA, though not many organisms were observed (Fig. 5C). As very few oligonucleotide probes were available, other filaments observed in the foam were identified based on their morphology, Gram-staining and Neisser staining properties as described by Jenkins et al. ${ }^{12)}$. Other species included Nostocoida limicola, type 1851, type 0041, type 1701, type 0675, type $021 \mathrm{n}$, type 0914 etc.

\section{Quantification of the foam formers before and after foaming}

To quantify the foam-forming organisms in the reactor before and after foaming, the FISH technique was used. The foam forming mycolata group was quantified using probe MYB with respect to probe EUB 338. The Microthrix parvicella population was also quantified with probe MPA223 with respect to probe EUB 338. The results of the quantification are shown in Table 3. Though it can be said that this quantification is not very accurate due to the drawbacks of the FISH technique (auto fluorescence, probe penetration etc.) itself, it still provides semi-quantitative or at least qualitative information about the relative abundance of the various species. The results showed that Microthrix parvicella was the dominant population in all the samples both before and after foaming.

Soddell ${ }^{22)}$ reviewed studies from all around the world about foam-forming microorganisms and concluded that Microthrix parvicella is a major cause of foaming in Europe, Australia and South Africa. The foaming mechanism requires three components-air bubbles, surfactants (synthetic or bio-surfactants produced by foam formers) and hydrophobic particles (hydrophobic bacteria which actually give the stability to the foam ${ }^{22}$. The high hydrophobicity of Microthrix parvicella cells has already been measured and described by various researchers ${ }^{22,25}$. So the capacity of Microthrix parvicella to produce foam is undoubtable. According to Hwang and Tanaka ${ }^{22)}$, Microthrix parvicella

Table 3. Quantification of foam former before and after foaming by FISH with the probes MYB, MPA223 and EUB 338.

\begin{tabular}{lcccc}
\hline \multicolumn{1}{c}{ Description of samples } & $\begin{array}{c}\text { MYB/EUB } \\
\text { (\% Mean) }\end{array}$ & Standard deviation & $\begin{array}{c}\text { MPA223/EUB } \\
\text { (\% Mean) }\end{array}$ & Standard deviation \\
\hline MLSS in March (before foaming) & 2.73 & 1.25 & 14.9 & 4.87 \\
MLSS in April (after foaming) & 1.21 & 0.43 & 8.21 & 2.11 \\
Foam (aeration tank) in April & 5.44 & 3.06 & 22.01 & 8.73 \\
Foam (non-aeration tank) in April & 6.16 & 1.75 & 22.37 & 7.14 \\
\hline
\end{tabular}


foaming has a typical seasonal pattern, that is foaming and SVI become intense during winter and spring and suppressed during summer and autumn. According to several in-depth studies ${ }^{15,17)}$, this phenomenon may be caused by both competitive psychrophilic growth, and concentrated Microthrix parvicella-degradable hydrophobic substrates at low temperature. But Knoop and Kunst ${ }^{13)}$ also suggested that Microthrix parvicella did not necessarily need long chain fatty acids for their growth as they can grow on a mixture of proteins, carbohydrate and fats as found in municipal wastewater. Foaming also occurred in this plant in spring (in April). So because 1) M. parvicella can grow in psychrophilic conditions, 2) $M$. parvicella can utilize various substrates and 3) the temperature in the plant was low and various substrates existed in the mixed liquor, the growth of $M$. parvicella was enhanced and foaming occurred. Due to all of the above facts it can be said undoubtedly that Microthrix parvicella was the main population responsible for this onset.

\section{Conclusions}

Various types of filaments were observed associated with the foam of a submerged MBR in Japan with morphological similarity to Nocardia spp., Microthrix parvicella, Nostocoida limicola, type 1851, type 0041, type 1701, type 0675 , type $021 \mathrm{n}$, type 0914 etc. Also with the help of available species-specific oligonucleotide probes (G.am, 21N, SNA and TNI) the presence of Gordona amarae, type 021N, Sphaerotilus natans and Thiothrix nivea was confirmed. With the probe MPA223 (specific to Microthrix parvicella), one of the most important and discussed filaments Microthrix parvicella was detected in the foam of this plant. The ratio of MPA to EUB (approx. 22\%) in the foam was found to be much higher than the ratio of MYB (group-specific probe for mycolata) to EUB (approx. 6\%). Foaming also occurred in this plant in spring, which is the season for maximum proliferation of Microthrix parvicella. Based on these facts it can be said undoubtedly that Microthrix parvicella was the main population responsible for the onset of foaming.

\section{References}

1) Amann, R.I. 1995. In situ identification of microorganisms by whole cell hybridization with rRNA-targeted nucleic acid probes. Molecular Microbial Ecology Manual 3.3.6: 1-15.

2) Bradford, D., C. Christensson, N. Jakab and L.L. Blackall. 1997. Molecular biological methods to detect "Microthrix Parvicella" and to determine its abundance in activated sludge. Proceedings
Second International Conference on Microorganisms in Activated Sludge and Biofilm Processes. July 21-23, Berkeley, California, USA, 181-187.

3) Davenport, R.J., T.P. Curtis, M. Goodfellow, F.M. Stainsby and M. Bingley. 2000. Quantitative use of fluorescent in situ hybridization to examine relationship between mycolic acid containing Actinomycetes. And foaming in activated sludge plants. Appl. Environ. Microbial. 66: 1158-1166.

4) De los Reyes, F.L., W. Ritter and L. Raskin. 1997. Groupspecific small subunit rRNA hybridyzation probes to characterize filamentous foaming in activated sludge systems. Appl. Environ. Microbial. 63: 1107-1117.

5) De los Reyes, F.L., D.B. Oerther, M.A. De los Reyes, M. Hernandez and L. Raskin. 1998. Characterization of filamentous foaming in activated sludge systems using oligonucleotide hybridization probes. Water Sci. Tech. 37: 485-493.

6) Erhart, R., D. Bradford, R.J. Seviour, R. Amann and L.L. Blackall. 1997. Development and use of fluorescent in situ hybridization probes for the detection and identification of Microthrix parvicella in activated sludge. System. Appl. Microbiol. 20: 310-318.

7) Goodfellow, M. 1992. The Family Nocardiaceae, p. 1188-1213. In A. Barlows, H.G. Truper, M. Dworkin, W. Harder, and K.-H. Schleifer (ed.), The Prokaryotes, 2nd ed., Vol. 2. SpringerVerlag, New York, N.Y.

8) Goodfellow, M., R. Davenport, F.M. Stainsby and T.P. Curtis. 1996. Actinomycetes diversity associated with foaming in activated sludge plants. J. Ind. Microbial. 17: 268-280.

9) Goodfellow, M., F.M. Stainsby, R. Davenport, J. Chun and T.P. Curtis. 1998. Activated sludge foaming: the true extent of Actinomycetes diversity. Water Sci. Tech. 37: 511-519.

10) Hiraoka, M. and K. Tsumura. 1984. Supression of actinomycete scum production: a case study at Senboku wastewater treatment plant, Japan. Water Sci. Tech. 16: 83-90.

11) Hwang, Y. and T. Tanaka. 1998. Control of Microthrix parvicella foaming in activated sludge. Water Res. 32: 1678-1686.

12) Jenkins, D., M.G. Richard and G.T. Daigger. 1993. Manual on the cause and control of the activated sludge bulking and foaming. 2nd edition, Lewis publishers, Michigan, USA.

13) Knoop, S. and S. Kunst. 1998. Influence of temperature and sludge loading on activated sludge settling, especially on Microthrix parvicella. Water Sci. Tech. 37: 27-35.

14) Mori, T., K. Itokazu, Y. Ishikura, F. Mishina, Y. Sakai and M. Koga. 1992. Evaluation of control strategies for actinomycete scum in Full-scale treatment plants. Water Sci. Tech. 25: 231237.

15) Richard, M. 1989. Activated Sludge Microbiology. The Water Pollution Control Federation.

16) Roller, C., M. Wagner, R. Amann, W. Ludwig and K.-H. Schleifer. 1994. In situ probing of gram - positive bacteria with high DNA $\mathrm{G}+\mathrm{C}$ content using $23 \mathrm{~S}$ rRNA-targetted ologonucleotides. Microbiology 140: 2849-2858.

17) Slijkhuis, H. and M.H. Deinema. 1988. Effect of Environmental conditions on the occurrence of Microthrix parvicella in activated sludge. Water Res. 22: 825-828.

18) Soddell, J.A. and R.J. Seviour. 1990. Microbiology of foaming in activated sludge plants—a review. J. Appl. Bacteriol. 69: 145176.

19) Soddell, J., G. Knight, W. Strachan and R. Seviou. 1992. Nocardioforms not nocardia foams. Water Sci. Tech. 26: 455-460. 
20) Soddell, J. and R. Seviour. 1995. Relationship between temperature and growth of organisms causing Nocardia foams in activated sludge plants. Water Res. 29: 1555-1558.

21) Soddell, J. and R. Seviour. 1998. Numerical taxonomy of Skermania piniformis and related isolates from activated sludge. J. Appl. Microbiol. 84: 272-284.

22) Soddell, J.A. 1998. Foaming. p. 161-202. In R.J. Seviour and L.L. Blackall (eds.), The Microbiology of Activated Sludge. Chapman \& Hall, London.

23) Trebesius, K., R. Amann, W. Ludwig, K. Muhlegger and K.-H.
Schleifer. 1994. Identification of whole fixed bacterial cells with nonradioactive 23 rRNA targeted polynucleotide probes. Appl. Environ. Microbial. 60: 3228-3235.

24) Wagner, M., R. Amann, P. Kampfer, B. Assmus, A. Hartmann, P. Hutzler, N. Springer and K.-H. Schleifer. 1994. Identification and in situ detection of gram-negative filamentous bacteria in activated sludge. System. Appl. Microbiol. 17: 405-417.

25) Westlund, A.D., E. Haglund and M. Rothman. 1998. Foaming in anaerobic digesters caused by Microthrix parvicella. Water Sci. Tech. 37: 51-55. 